\title{
Electrochemical characterization of doped-diamond-coated carbon fibers at different boron concentrations
}

\author{
E. C. Almeida ${ }^{1}$, A. V. Diniz ${ }^{1}$, V.J. Trava-Airoldi ${ }^{1}$ and N. G. Ferreira ${ }^{2}$ \\ ${ }^{1}$ INPE - C. P. 515 - 12201-970 - São José dos Campos, S.P., Brasil \\ ${ }^{2}$ CTA-Divisão de Materiais- 12228-904 - São José dos Campos, S.P., Brasil \\ erica@las.inpe.br
}

Keywords: carbon fibers, diamond films, doping p-type , electrode arrangement

\begin{abstract}
Doped-diamond films have been deposited on carbon fibers (felt) obtained from Polyacrylonitrile (PAN) at different levels of boron doping. For a successful coating of the fibers an ultrassonic pretreatment in a bath of diamond powder dissolved in hexane was required. Films were grown on both sample sides, simultaneously, by Hot-Filament-assisted Chemical Vapour Deposition (HFCVD) technique at $750{ }^{\circ} \mathrm{C}$ from a $0.5 \% \mathrm{H}_{2} / \mathrm{CH}_{4}$ mixture at a total pressure of $6.5 \times 10^{3} \mathrm{~Pa}$. Boron was obtained from $\mathrm{H}_{2}$ forced to pass through a bubbler containing $\mathrm{B}_{2} \mathrm{O}_{3}$ dissolved in methanol. The doping level studied corresponds to films with the acceptor concentrations in the range of $6.5 \times 10^{18}$ to $1.5 \times 10^{21} \mathrm{~cm}^{-3}$, obtained from MottSchottky plots. Scanning Electron Microscopy (SEM) analyses evidenced fibers totally covered with high quality polycrystalline boron doped diamond film also confirmed by Raman spectroscopy spectra. Diamond electrodes grown on carbon fibers demonstrated similar electrochemical behavior obtained from films on Si substrate, for ferri/ferrocyanide redox couple as a function of boron content. The boron content influences the electrochemical surface area. Lower boron concentration provides higher growth rate that resulting in the higher surface area.
\end{abstract}




\section{Introduction}

The wide electrochemical applications of carbon-based electrodes has provided a constant search of developing new materials due to their importance for surface sensitive electrode process, where durability and efficiency are required. Diamond electrodes grown on different substrates have a particular remarkable for electrochemical study by offering high sensitivity, good precision and high stability when compared with glassy carbon and platinum electrodes [1-7].

Most of our works [8,9] has involved using diamond films grown on Si substrates. These results have indicated that diamond films exhibit lower voltammetry background currents and larger $\mathrm{S} / \mathrm{B}$ ratios for ferrocyanide $/ 0.1 \mathrm{M} \mathrm{KCl}$ and hydroquinone $/ 1 \mathrm{M} \mathrm{Na}_{2} \mathrm{SO}_{4}$ redox couples without any conventional surface pretreatment. Thus, as diamond electrode not suffers changes in its physicochemical surface properties; it presents all desirable qualities of advance electrode materials for using in electroanalysis.

By considering electrochemical applications where carbon electrodes are frequently used, as anode in organic electrochemistry [10], the association of diamond films with carbon substrate becomes as an alternative for increasing the electrode lifetime. Besides, the resistivity of diamond films may be controlled by the level of boron doping. This control process guarantees the suitable electrode conductivity keeping its necessary chemical inertness [8].

Diamond growth mechanisms on carbon fibers have already discussed by some authors [11-13]. It is known that the diamond deposition on carbon substrate using low pressure techniques may be unfavorable due to the etching of atomic hydrogen. The authors generally accepted that the supersaturation of hydrogen enhances the formation of diamond and suppresses the formation of nondiamond phases. Angus and coworks [14] have reported the 
nucleation of diamond on graphite and suggest that this graphite surface itself acts as a nucleation center in the presence of atomic hydrogen.

In this article we report the results of successful growth of doped diamond on no woven of carbon fibers (felts) at different levels of boron concentrations. The main purpose was to investigate the electrochemical response of this new electrode using scan cyclic voltammetry and compared to the diamond/Si electrodes that have well-defined characteristics [8]. The boron content influence on diamond/felt electrodes was also investigated for ferri/ferrocyanide redox couple and revealed a quasi-reversible behavior. The increasing of electrochemical surface is correlated to lower boron concentration that provides higher growth rate for such films.

\section{Experimetal details}

Carbon felts are made from fibers of organic polymers such as Polyacrylonitrile (PAN). These precursor fibers are heated in a nitrogen environment until volatile products are given off and the carbon fibers are composed of at least $92 \%$ carbon. The temperature used to treat the fibers was $2000^{\circ} \mathrm{C}$ by using the temperature steps of $60^{\circ} \mathrm{C} / \mathrm{h}$ in a nitrogen atmosphere up to $1000{ }^{\circ} \mathrm{C}$ and for more $4 \mathrm{~h}$ until $2000{ }^{\circ} \mathrm{C}$. The samples consist of felt disks with $0.15 \mathrm{~cm}$ thickness and $1.0 \mathrm{~cm}$ diameter.

Boron doped-diamond films were grown by Hot-Filament-assisted Chemical Vapour $\underline{\text { Deposition (HFCVD) technique at } 750{ }^{\circ} \mathrm{C} \text { from a } 0.5 \% \mathrm{H}_{2}} \underline{2} \underline{\mathrm{CH}}_{4} \underline{\text { mixture at a total pressure of }}$ $\underline{6.5 \times 10^{3} \mathrm{~Pa} \text {. during } 19 \text { hours. The substrates were ultrasonically pre-treated in a mixture of }}$

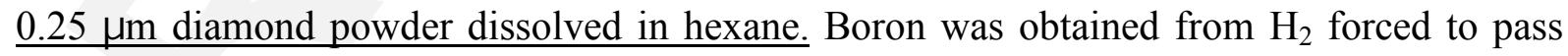
through a bubbler containing $\mathrm{B}_{2} \mathrm{O}_{3}$ dissolved in methanol. This system permits the control of boron concentration using a flow controller for the gas inlet. For all experiments the $\mathrm{H}_{2}$ and $\mathrm{B}_{2} \mathrm{O}_{3} / \mathrm{CH}_{3} \mathrm{OH} / \mathrm{H}_{2}$ flows were controlled in order to obtain the desired $\mathrm{B} / \mathrm{C}$ ratios. The 
dissolution of $2000,5000,10000$ and 20000 ppm of $\mathrm{B}_{2} \mathrm{O}_{3}$ in methanol was necessary to cover the whole range of $\mathrm{B} / \mathrm{C}$ ratios studied. These doping level studied correspond to acceptor concentrations in the range of $6.5 \times 10^{18}$ up to $1.5 \times 10^{21} \mathrm{~cm}^{-3}$, obtained from Mott-Schottky plots measurements in previous work [8] and also correlated with Raman spectra [16].

Samples were kept in the vertical position inside the reactor between two pairs of parallel tungsten filaments, as shown in Fig 1a, which permitted the film growth on both sides, simultaneously. This procedure is important for guarantying the diamond growth on the surface and center sample. The electrode arrangement can be seen in Figure 1b, where the diamond film is mounted inside two Teflon rings keeping it in the solution isolated to the electric contact. From this arrangement the electrode geometric surface area exposit in the solution is $2.0 \mathrm{~cm}^{2}$. Top view and cross-section images of diamond films were obtained by Scanning Electron Microscopy (SEM) from LEO 440 and JEOL-JSM-5310, respectively. The SEM images were obtained using acceleration voltage of $20 \mathrm{kV}$ and working distance were $25 \mathrm{~mm}$ in both the equipment. Micro-Raman spectra were recorded by a Renishaw microscope system 2000 in backscattering configuration at room temperature employing $\underline{514.5 \mathrm{~nm} \text { argon-ion laser. }}$

Cyclic voltammetric measurements were carried out using a Microquímica potentiostat model MQPG-01 for diamond/felt electrodes at different doping levels. The anodic and cathodic charge was evaluated in $1 \mathrm{mM}$ of ferrocyanide/ $0.1 \mathrm{M} \mathrm{KCl}$ at a scan rate in the range of 5 up to $500 \mathrm{mV} \cdot \mathrm{s}^{-1}$. The experiments were conducted at room temperature. A simple three-electrode (work electrode, counter electrode, reference electrode), singlecompartment electrochemical cell was used in this study. The electrodes did not undergo surface pretreatment before the electrochemical measurements. For all electrochemical measurements reference and counter electrodes of $\mathrm{Ag} / \mathrm{AgCl}$ and platinum were used, respectively. 


\section{Results and discussion}

\subsection{Surface morphology and Raman analysis}

The main difficulty of growing diamond films on graphite is the $\mathrm{sp}^{2}$ bond etches on the substrate, caused by atomic hydrogen present in the gas phase, which is the main precursor for diamond growth. The suitable substrate pre-treatment is necessary to improve the diamond growth on carbon substrate keeping the surface carbon in $\mathrm{sp}^{3}$ configuration dominant over reconstruction into graphitic $\mathrm{sp}^{2}$. In this work, the treatment applied was adequate. SEM image of diamond/felt electrode is depicted in Fig.2A and demonstrates that the carbon fibers were completely covered by a diamond polycrystalline film. The micrograph represents a sample for a doping level of $5000 \mathrm{ppm} \mathrm{B/C} \mathrm{dissolved} \mathrm{in} \mathrm{methanol} \mathrm{corresponding}$ to approximately $10^{19}$ atoms.cm ${ }^{-3}$. The grains are faceted with symmetrical and smooth faces with uniform texture and a surface morphology with (111) and (100) type planes.

A small variation at the average grain size was also observed as a function of the boron content in the range of 3.5 up to $2.5 \mu \mathrm{m}$ for a doping level studied between 2000 and $20000 \mathrm{ppm}$, related to the decreasing of growth rate which influences the electrode surface area. This result was already observed and is consistent for a plain electrode as a doped diamond/Si film [17]. In the case of a three-dimensional porous electrode, formed by diamond/carbon fiber, this process is not simple and different contributions should be considered. First of all, the film is grown around the fibers increasing their diameters by resulting in the area increasing for each fiber. Consequently, higher doping level promotes a lower growth rate and a lower fiber surface area. It seems to decrease the total surface area. Besides, lower growth rate evidences smaller grain size and roughness. Otherwise, the contribution from films with lower doping level is related with larger grain size and larger fiber diameter that filling empty spaces between the same ones and consequently decreases 
the porosity. This contribution would tend to diminish the superficial area in the case of less doped films.

Surface diamond-coated fibers have presented a thickness of around $3.0 \mu \mathrm{m}$ that decreases for internal fibers, as expected, taking into account the critical depth for diamond formation, mainly due to the atomic hydrogen diffusion mechanisms. Figure $2 \mathrm{~B}$ represents a fiber cross-sectional SEM image in the center sample region and still evidences a diamond film. This analysis is important for electrochemical applications by considering this samples as a three dimensional electrode and the inner fibers also need to be covered by diamond film. Surface texture electrode is directly related with the electrode active area and, consequently, with the electrochemical response.

The quality and doping level of the films grown on felt of carbon fibers were studied by Raman spectroscopy. A drastic change of Raman spectra of diamond films with different doping levels was observed. Figure 3 shows the Raman spectra for a carbon fiber (curve a) and diamond/felt films with doping level of 2000 and 20000 ppm, respectively. A typical two bands spectrum of carbon fiber heat treated at $1000{ }^{\circ} \mathrm{C}$ in nitrogen atmosphere is evidenced in curve $a$. The band at $1575 \mathrm{~cm}^{-1}$ is attributed to the graphite basal plane $\mathrm{G}$ band, while the band at $1355 \mathrm{~cm}^{-1}$ may be associated with disordered D band [18]. For diamond films, curves $b$ and $c$, the results reveal that the peak intensity at $1332 \mathrm{~cm}^{-1}$ corresponding to the transversal mode (related to the $\mathrm{sp}^{3}$ bonds) of the diamond decreases as the boron concentration increases. Nevertheless, a wide band arises approximately $1220 \mathrm{~cm}^{-1}$ and increases as the boron concentration increase, as shown in Figure 3c. The decrease of the zone center phonon peak at $1332 \mathrm{~cm}^{-1}$ and the appearance of the broad peak at $1220 \mathrm{~cm}^{-1}$ was attributed to the relaxation of the $\Delta \kappa=0$ selection rule caused by the small coherence length of diamond crystallites [19-20]. 


\subsection{Electrochemical Behavior}

Cyclic voltammetry has demonstrated to be an easy and fast method to study the electrochemical response of the surface electrode. Several works have presented important studies from this technique for boron-doped diamond electrodes [21-24]. This work presents a simple electrochemical analysis of diamond/felt electrodes as a function of the boron content. The main objective is to compare if such electrodes grown on carbon fibers present the same electrochemical behavior of the standard electrodes grown on silicon substrates [8], besides promoting a higher electrochemical surface area.

Voltametric study has shown that the diamond/felt electrodes may be analyzed by the quasi-reversibility criteria: $\Delta E_{\mathrm{p}}$ is larger than $59 / n \mathrm{mV}$ and increase with sweeping rate $(v)$ increase, current peak intensity $\left(I_{\mathrm{p}}\right)$ increases with $v^{1 / 2}$ increase, but do not keep the proportionality; and the cathodic peak potential, $E_{\mathrm{Pc}}$ shifts to negative value, with the $v$ increase. This analysis was associated with the kinetics parameters, $\Delta E_{\mathrm{p}}$ and $I_{\mathrm{Pc}}$ as functions of the doping level and sweeping rate [25]. The treatment of systems called quasi-reversible is associated with reactions that show electron transfer kinetic limitations where the reverse reaction has to be considered. The results presented in our experiments have led us to conclude that this is the more suitable treatment for such diamond/felt electrodes for the redox system studied, mainly due to the range of $\Delta E_{\mathrm{P}}$ obtained as a function of sweeping rate. Electrochemical response also permitted to evaluate the electrode Specific Electrochemical Surface Area (SESA) in $\left(\mathrm{cm}^{2} \cdot \mathrm{cm}^{-3}\right)$.

Cyclic voltammetric curves for the ferri/ferrocyanide redox couple exhibited the usual set of reduction and oxidation current peaks for all electrodes studied. Figure 4 presents voltammetric curves for felt and diamond/felt electrodes in $1 \mathrm{mM}$ of ferrocyanide/ $0.1 \mathrm{M} \mathrm{KCl}$ at $\underline{v=100 \mathrm{mV} / \mathrm{s}}$. For better visualization are shown only two doping levels of 2000 and 2000 
ppm B/C, but the behavior is similar for all electrodes. The sweeping rate increasing promotes an increasing of current peak intensity in cathodic and anodic reactions.

By using the quasi-reversibility criteria, the separation between the anodic and cathodic peaks, $\Delta E_{p}$, increases with $v$ increases and it is larger than $59 / n \mathrm{mV}$ (where $n=1$ is the number of electrons involved in the reaction). From Fig. 5, it can verify the $\Delta E_{p}$ increase with increase $v$, which correspond a quasi reversibility criteria. Other important aspect is related to variation of $\Delta E_{p}$ for a felt electrode is always higher than for diamond/felt electrodes also indicating the good conductivity of diamond film in the range of doping level studied.

The quasi-reversibility characteristics are confirmed by the data obtained for all electrodes as observed in Fig. 6 and 7, correspond to the increase of cathodic peak current and $E_{\mathrm{Pc}}$ shifts to negative value as a function of the sweeping rate square root, respectively. All experiments have been compared to felt electrode. Although carbon fibers present a conductive characteristic, doped diamond/felt electrodes confirm their singular properties for the electron-transfer kinetics of a given redox analyte, mainly due to their surface stability and low background current.

The anodic peak current was also used to evaluate the SESA, which is obtained by equation [26]:

$$
\mathrm{SESA}=\frac{I_{p}}{2,69 \times 10^{5} C_{o} V_{e l} \sqrt{D_{o} v}}
$$

where $I_{p}$ is anodic peak current intensity (A), $C_{o}$ is oxidant concentration $(\mathrm{mol} / \mathrm{L}$, equal to reductor), $V_{e l}$ is de electrode volume immersed in solution $\left(\mathrm{cm}^{3}\right), D_{o}$ is oxidant difusivity in solution $\left(\mathrm{cm}^{2} \cdot \mathrm{s}^{-1}\right.$, also considered equal to reductor), e $v$ is sweeping rate in voltammetric 
experiment $\left(\mathrm{V}^{-1}{ }^{-1}\right)$. SESA values are shown in Fig. 8 for such diamond/felt electrodes as a function of boron concentration. The surface area increase is of around 6 times for 2000 and $5000 \mathrm{ppm} \mathrm{B} / \mathrm{C}$ diamond/felt electrodes when compared with felt electrode. As the boron incorporation increases the real surface are decreases. This result is consistent with the behavior observed for boron-doped diamond films, since the growth rate decreases with the boron incorporation. In addition, the anodic charge may also depend on surface process as the oxygen and hydrogen content in such films. It is important to remember that the boron source in the experimental process is obtained from $\mathrm{B}_{2} \mathrm{O}_{3}$ dissolved in methanol. For an anodic scan, oxygen atoms can replace the hydrogen atoms and the surface states can drastically change.

\section{Conclusions}

By controlling the suitable pretreatement in ultrasonic bath included diamond powder, continuous diamond films can be deposited on carbon fibers. SEM analyses have demonstrated a high nucleation and coalescence of doped diamond films with uniform morphology and good quality around the carbon fibers at different boron concentration. The boron content also influence the surface area associated to the average grain size. Lower boron concentration provide higher growth rate that result a higher surface area. Diamond/felt electrodes demonstrated similar electrochemical behavior, compared to diamond/Si electrodes, for quasi-reversible systems as a function of boron content. In addition, the cathodic peak current as a function of square root of the sweeping rate presents a linear behavior. This behavior indicated to be very attractive the association of diamond films with carbon substrate as an alternative for way obtaining a new electrode with higher lifetime. Besides, the resistivity of diamond films may be controlled by the boron doping concentration. In addition, the evaluation of SESA for diamond/felt electrodes associated with their singular properties in aqueous electrolytes, have demonstrated that such electrodes are very promising for electrochemical capacitor applications. 


\section{Referências}

[1] H. Spicka, M. Griesser, H. Hutter, M. Grasserbauer, S. Bohr, R. Haubner, B. Lux, Diamond Relat. Mater. 5 (1996) 383.

[2] G.R. Brandes, C.P. Beetz, C.A. Feger, R.L. Wright, Diamond. Relat. Mater. 4 (1995) 586.

[3] R. Rameshan, R.F. Askew, M.F. Rose and B.H. Loo, J. Electrochem. Soc. 140 (1993) 3018.

[4] G.M. Swain, J. Electrochem. Soc. 141 (1994) 3382.

[5] A.D. Modestov, Yu.E. Evstefeeva, Yu.V. Pleskov, V.M. Mazin, V.P. Varnin and I.G. Teremetskaya, J. Electroanal. Chem. 431 (1997) 211.

[6] Yu.V. Pleskov, Yu.E. Evstefeeva, M.D. Krotova, V.V. Elkin, A.M. Baranov and A.P. Dement'ev, Diamond. Relat. Mater. 8 (1999) 64.

[7] J.C. Angus, H.B. Martin, U. Landau, Y.E. Evstefeeva, B. Miller, N. Vinokur, New Diamond Front. Carbon Technol. 9 (1999) 175.

[8] N.G. Ferreira, L.L. G. Silva, E.J. Corat, V.J. Trava-Airoldi, Diamond Relat. Mater. 11 (2002) 1523.

[9] N.G. Ferreira, L.L.G. Silva, E.J. Corat, V.J. Trava-Airoldi , K. Iha, Braz. J. Phys., 29 (1999) 760.

[10] R. Ramesham, Thin Solid Films 339 (1999) 82.

[11] S.I. Shah, M.M. Waite, J. Vac. Sci. Technol., A 13 (1995) 1624.

[12] J. Tin and M.L. Lake, J. Mater. Res. 9 (1994) 636.

[13] P.E. Pehrsson, J. Glesener and A. Morrish, Thin Solid Films 212 (1992) 81.

[14] Z.Li, L. Wang, T. Suzuki, A. Argoitia, P. Pirouz and J.C. Angus, J. Appl. Phys. 73 (1993) 711. 
[15] R.C. Mendes de Barros, E.J. Corat, N.G. Ferreira, T.M. Souza, V.J. Trava-Airoldi, N.F. Leite and K. Iha, Diamond Relat. Mater. 5 (1996) 1323.

[16] R.J. Zhang, S.T. Lee, Y.M. Lam, Diamond Relat. Mater. 5 (1996) 1288.

[17] N.G. Ferreira, L.L.G. Silva, E. J. Corat, Diamond. Relat. Mater. 11 (2002) 657

[18] L.H. Peebles, Carbon Fibers: Formation, Structure and Properties, CRC Press, Florida, 1995.

[19] R.J. Nemanich, J.T. Glass, G. Lukovsky, R.E. Shroder, J. Va. Sci. Technol., A6 (1988) 1783.

[20] C.L. Clement, F. Zenia, N.A. Ndao, A. Deneuville, New Diamond Front. Carbon Technol. 19 (1999) 189.

[21] G.M. Swain and R. Ramesham. Anal. Chem. 65 (1993) 345.

[22] R. Ramesham and M.F. Rose, J. Mater. Sci. Lett. 16, 799 (1997).

[23] K. Patel, K. Hashimoto, and A. Fujishima, J. Photochem. Photobiol., A: Chem., 65 (1992) 419.

[24] Yu.V. Pleskov, V.V. Elkin, M.A. Abaturov, M. D. Krotova, V. Ya Mishuk, V. P. Varnun, I.G. Teremetskaya, J. Electroanal. Chem., 413 (1996) 105.

[25] R. Greef, R. Peat, L.M Peter, D. Pletcher, J. Robinson, Instrumental Methods in Electrochemistry, ch. 6, Wiley, NewYork, 1985.

[26] S. Trassatti, O.A Petrii, Pure Appl. Chem., 5 (1991) 711. 


\section{Figure Captions}

Figure 1. (a) Experimental setup for diamond/felt electrode growth. (b) Electrode arrangement for cyclic voltammetry measurements.

Figure 2. SEM images of diamond/felt electrode for a doping level of $5000 \mathrm{ppm} \mathrm{B/C}$. (A) morphology; (B) cross section evidencing the inner fiber.

Figure 3. Raman spectra for a carbon fiber (curve a) and diamond/felt films with doping level of 2000 (curve b) and 20000 ppm (curve c), respectively.

Figure 4. Cyclic voltammetry of felt and diamond/felt electrodes in $1 \mathrm{mmol} / \mathrm{L}$ ferrocyanide/ $0.1 \mathrm{~mol} / \mathrm{L} \mathrm{KCl}$ at sweeping rate of $100 \mathrm{mV} / \mathrm{s}$ : (a) felt; (b) diamond/felt $2000 \mathrm{ppm}$; (c) diamond/felt $20000 \mathrm{ppm}$. The solid, dot and dash lines correspond to the diamond / felt $-20000 \mathrm{ppm}$, diamond / felt -2000 and felt, respectively.

Figure 5. $\Delta \mathrm{Ep}$ as a function of sweeping rate in $1 \mathrm{mmol} / \mathrm{L}$ ferrocyanide/ $0.1 \mathrm{~mol} / \mathrm{L} \mathrm{KCl}$ for:

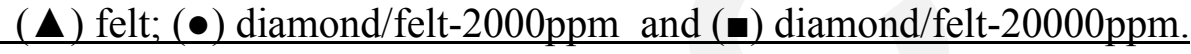

Figure 6. Cathodic potential as a function of sweet rate in $1 \mathrm{mmol} / \mathrm{L}$ ferrocyanide $/ 0.1 \mathrm{~mol} / \mathrm{L}$ $\underline{\mathrm{KCl} \text { for: }(\boldsymbol{\Delta}) \text { felt; }(\bullet) \text { diamond/felt-2000ppm and }(\boldsymbol{\square}) \text { diamond/felt-20000ppm. }}$

Figure 7. Cathodic peak current as a function of (sweet rate) ${ }^{1 / 2}$ in $1 \mathrm{mmol} / \mathrm{L}$ ferrocyanide / 0.1 mol/L KCl for: $(\boldsymbol{\Delta})$ felt; $(\bullet)$ diamond/felt-2000ppm and ( $\boldsymbol{\bullet})$ diamond/felt$\underline{20000 \mathrm{ppm}}$.

Figure 8. SESA for felt and diamond/felt electrodes in $1 \mathrm{mmol} / \mathrm{L}$ ferrocyanide $/ 0.1 \mathrm{~mol} / \mathrm{L} \mathrm{KCl}$ at $100 \mathrm{mV} / \mathrm{s}$ as a function of boron concentration. 


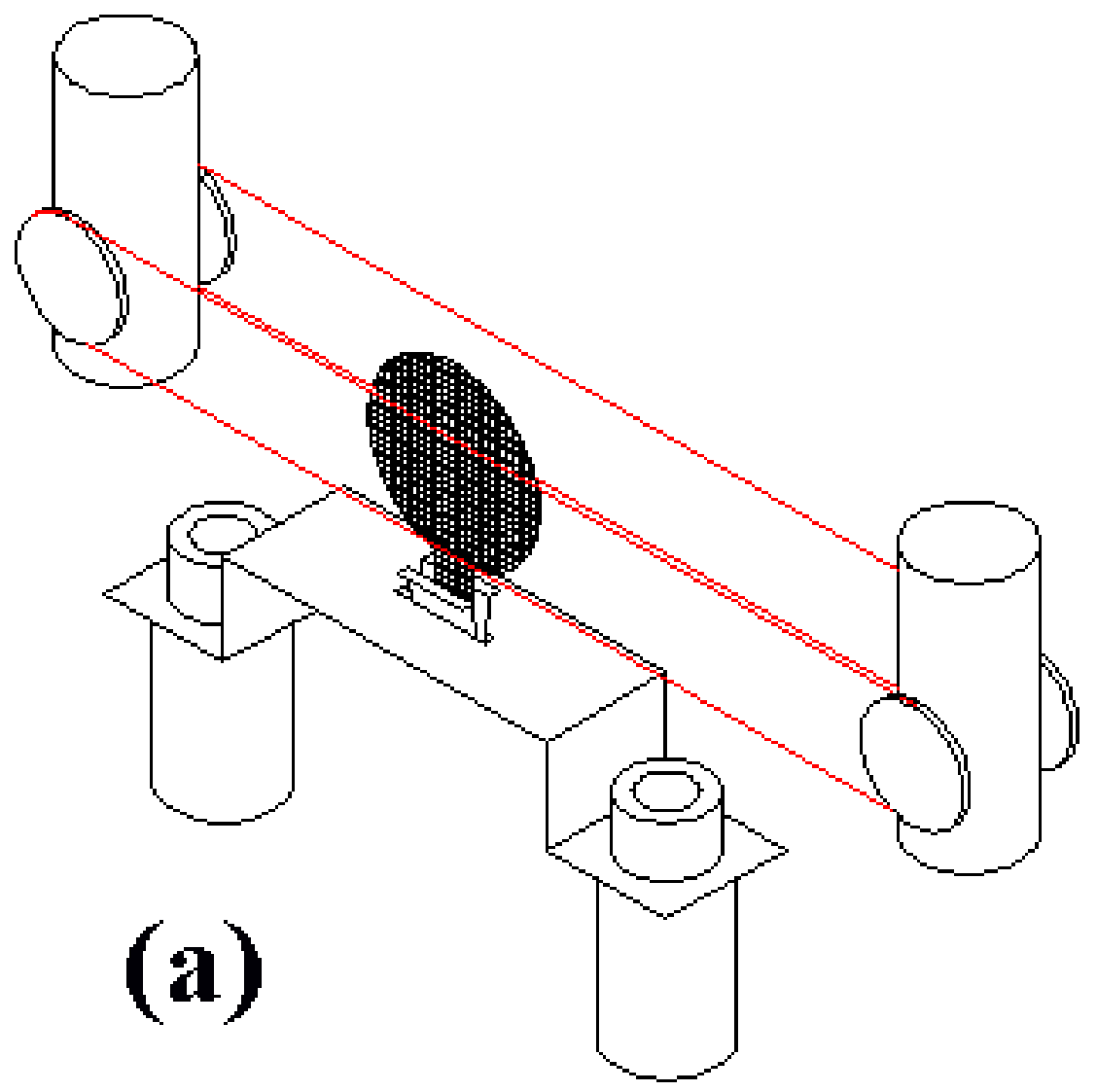

Figure $1 \mathrm{a}$ 


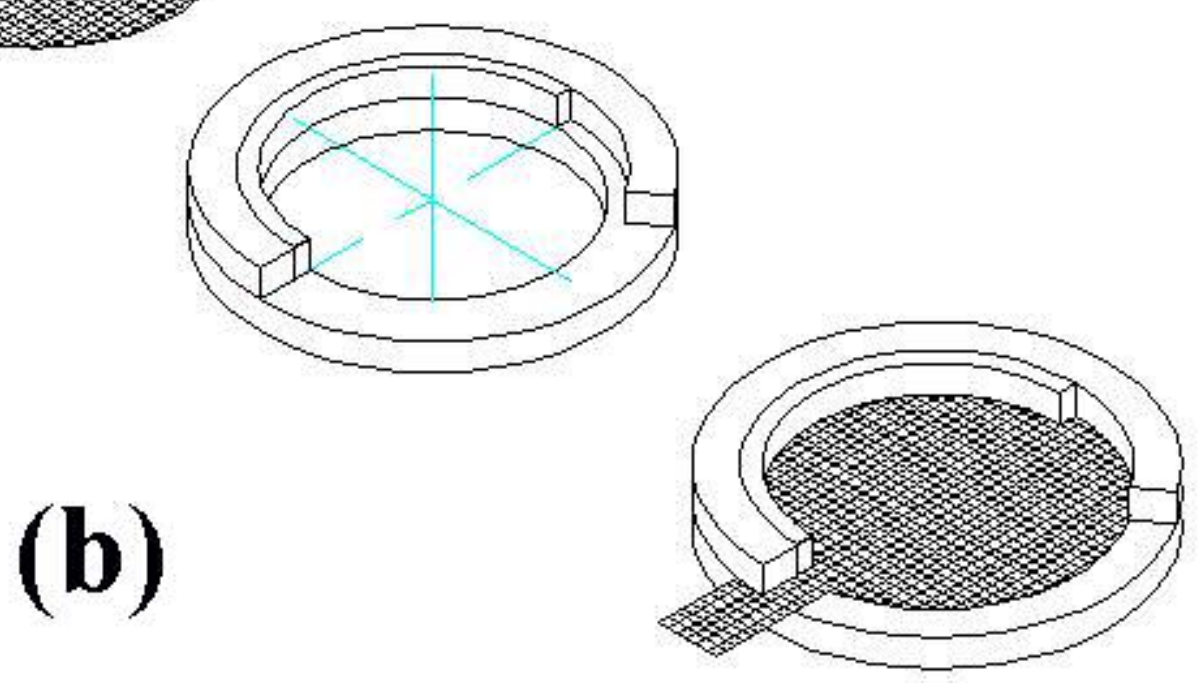

Figure 1b 


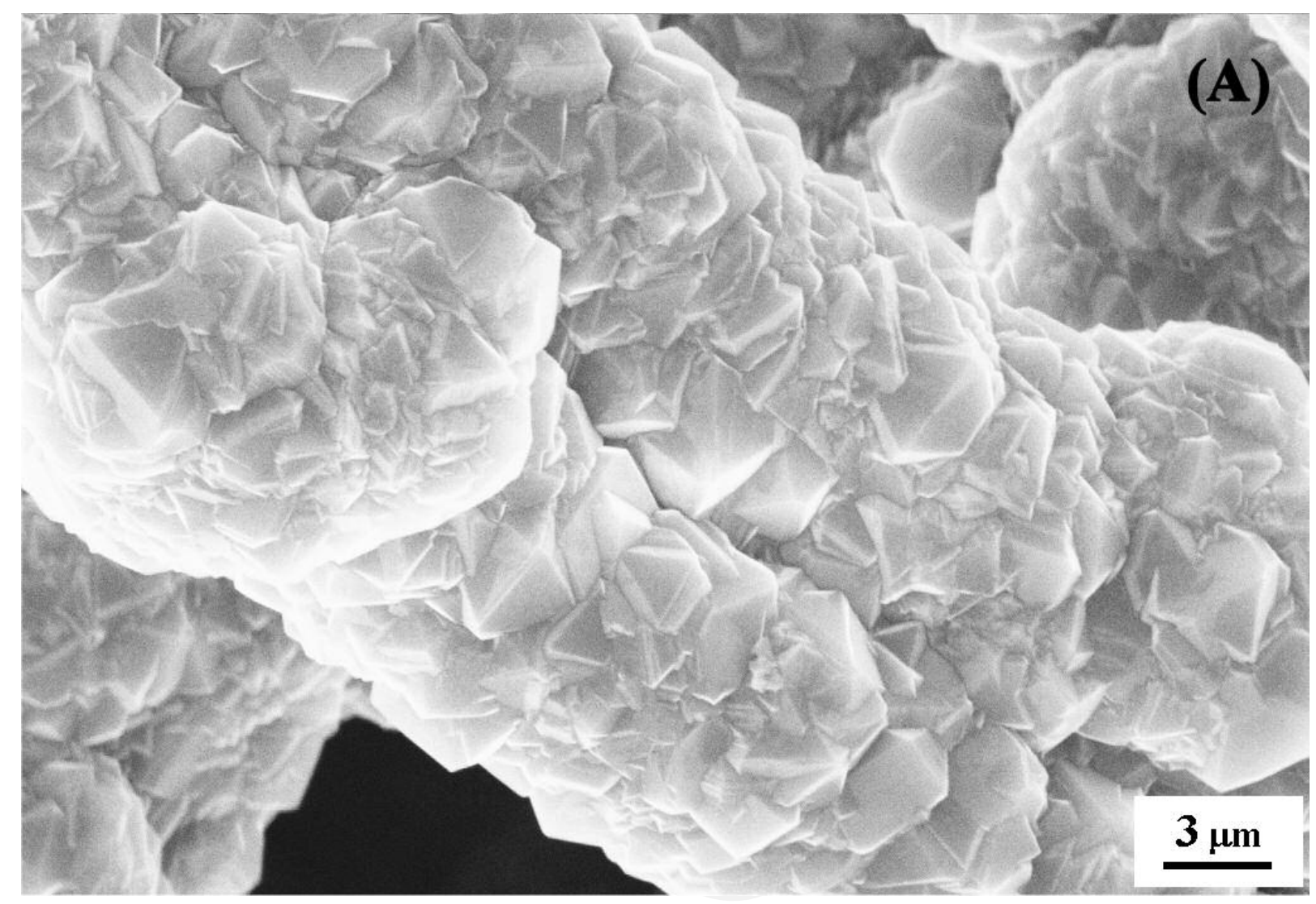

Figure $2 \mathrm{a}$ 


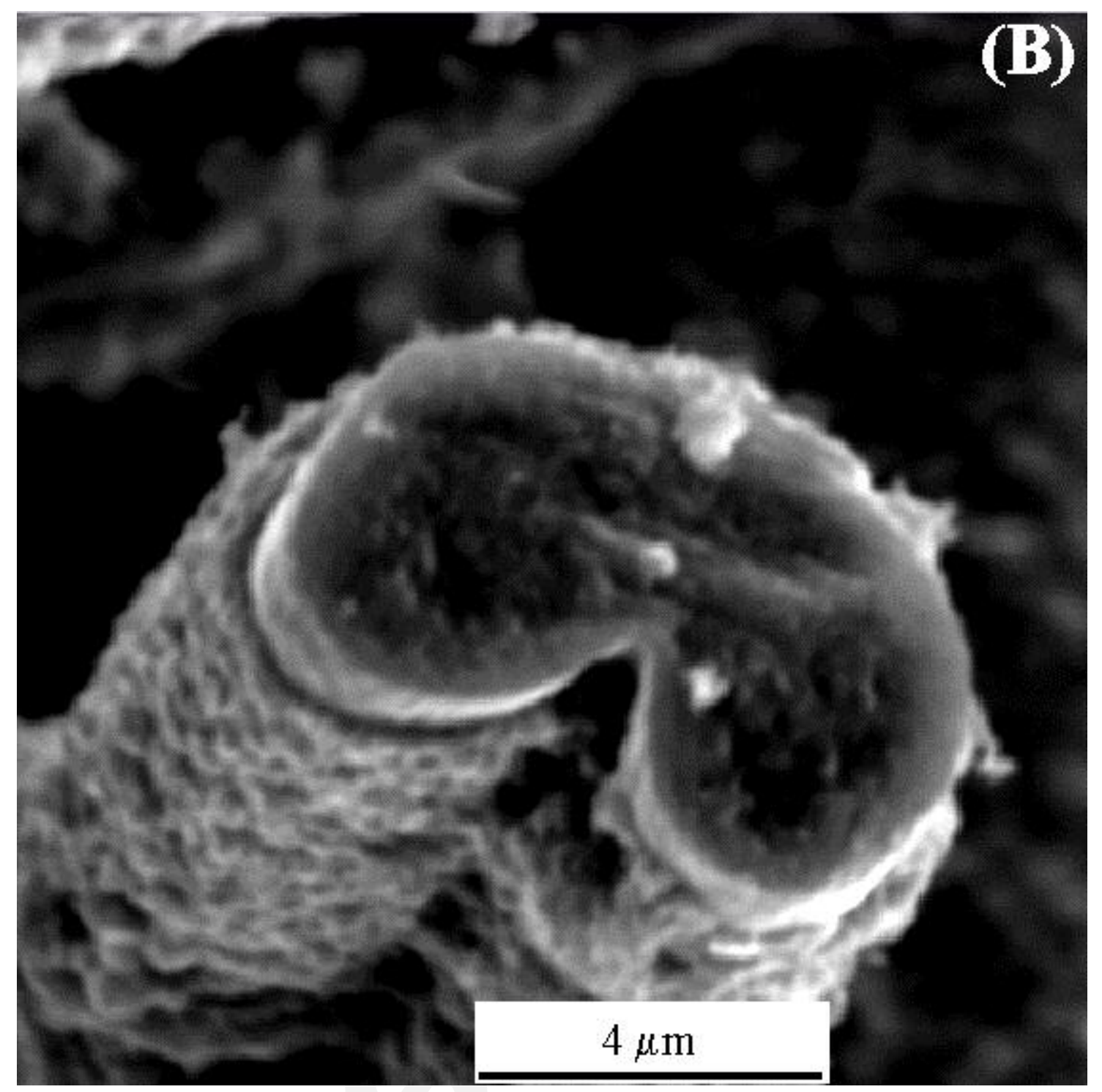

Figure $2 b$ 


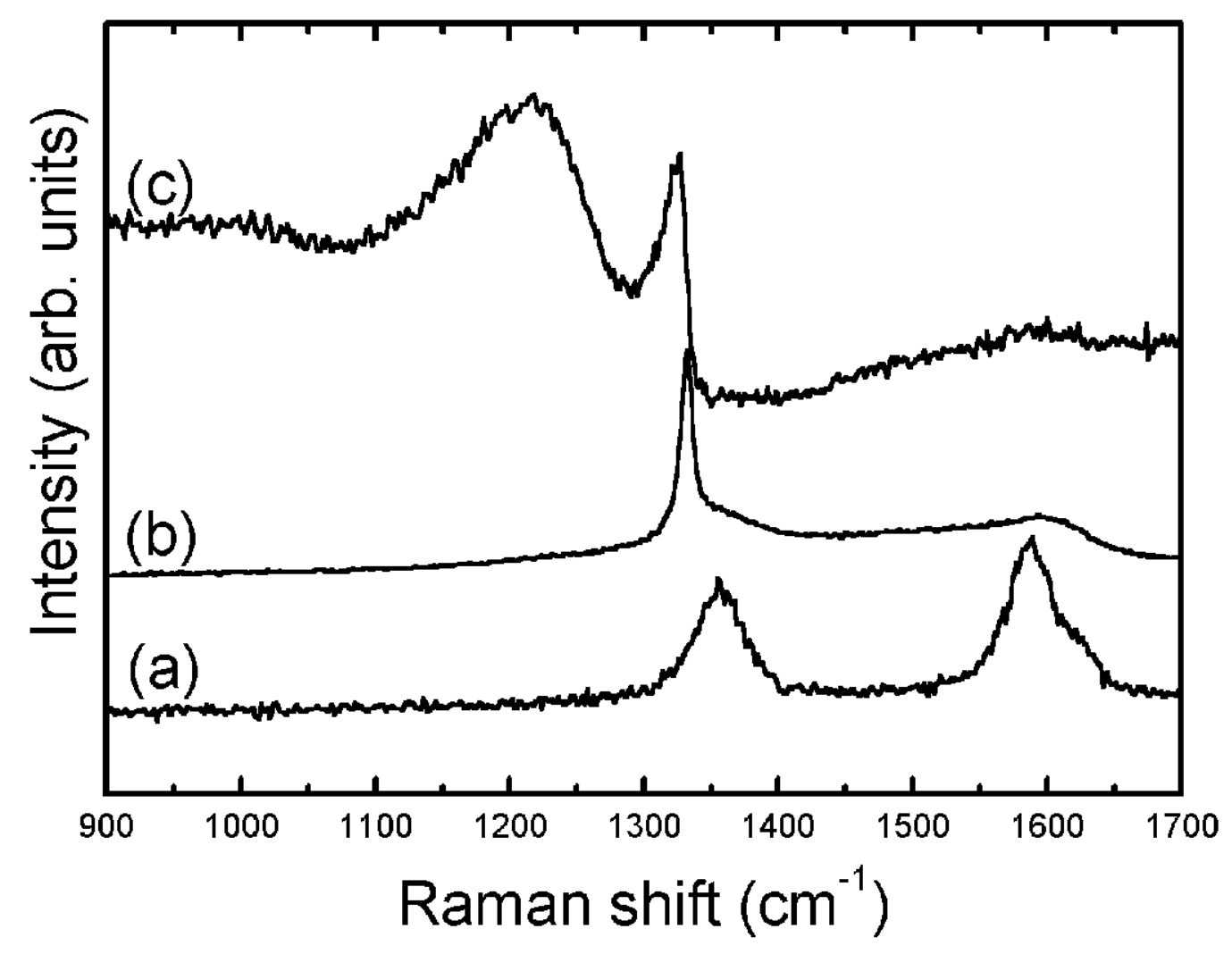

Figure 3 


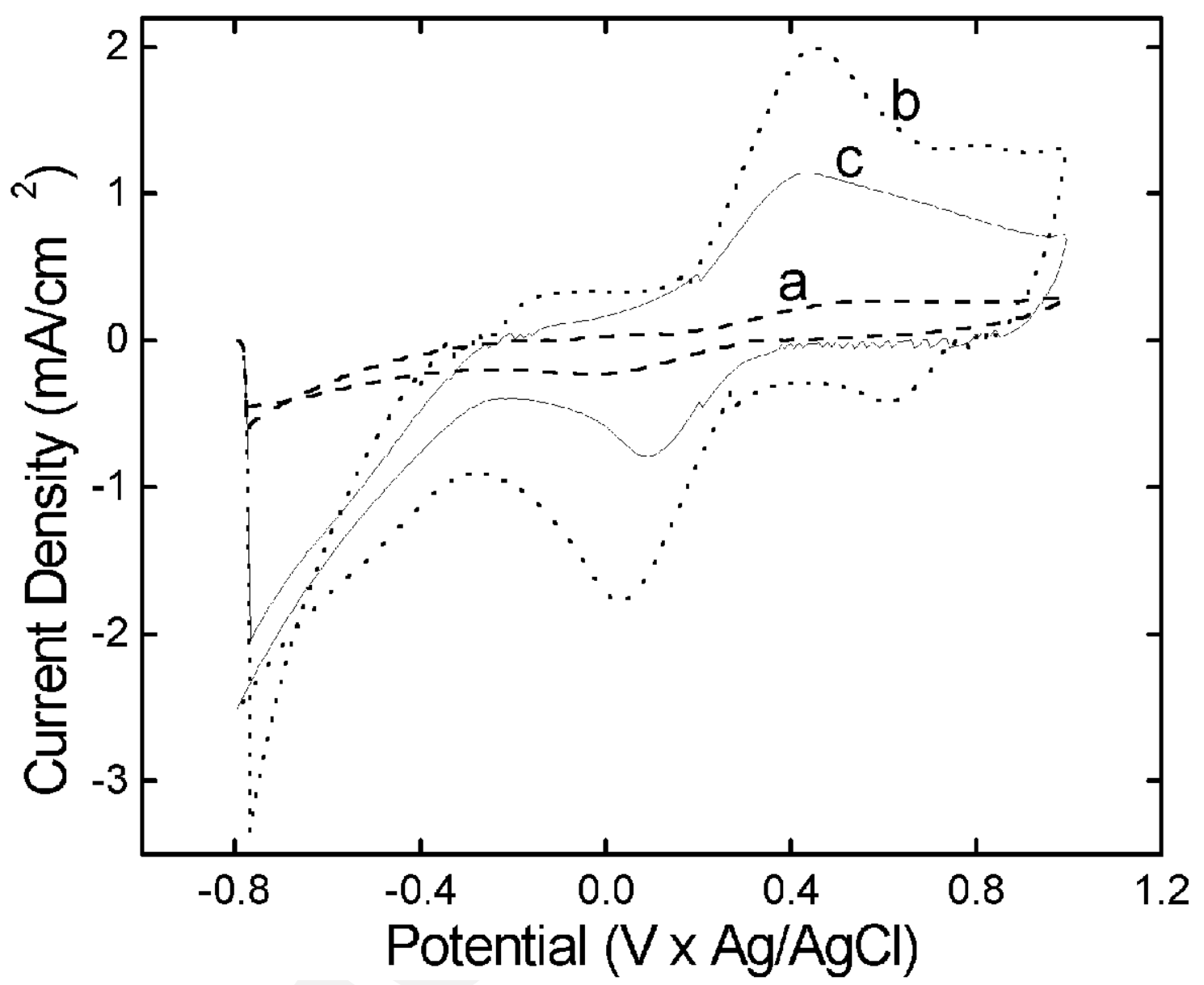

Figure 4 


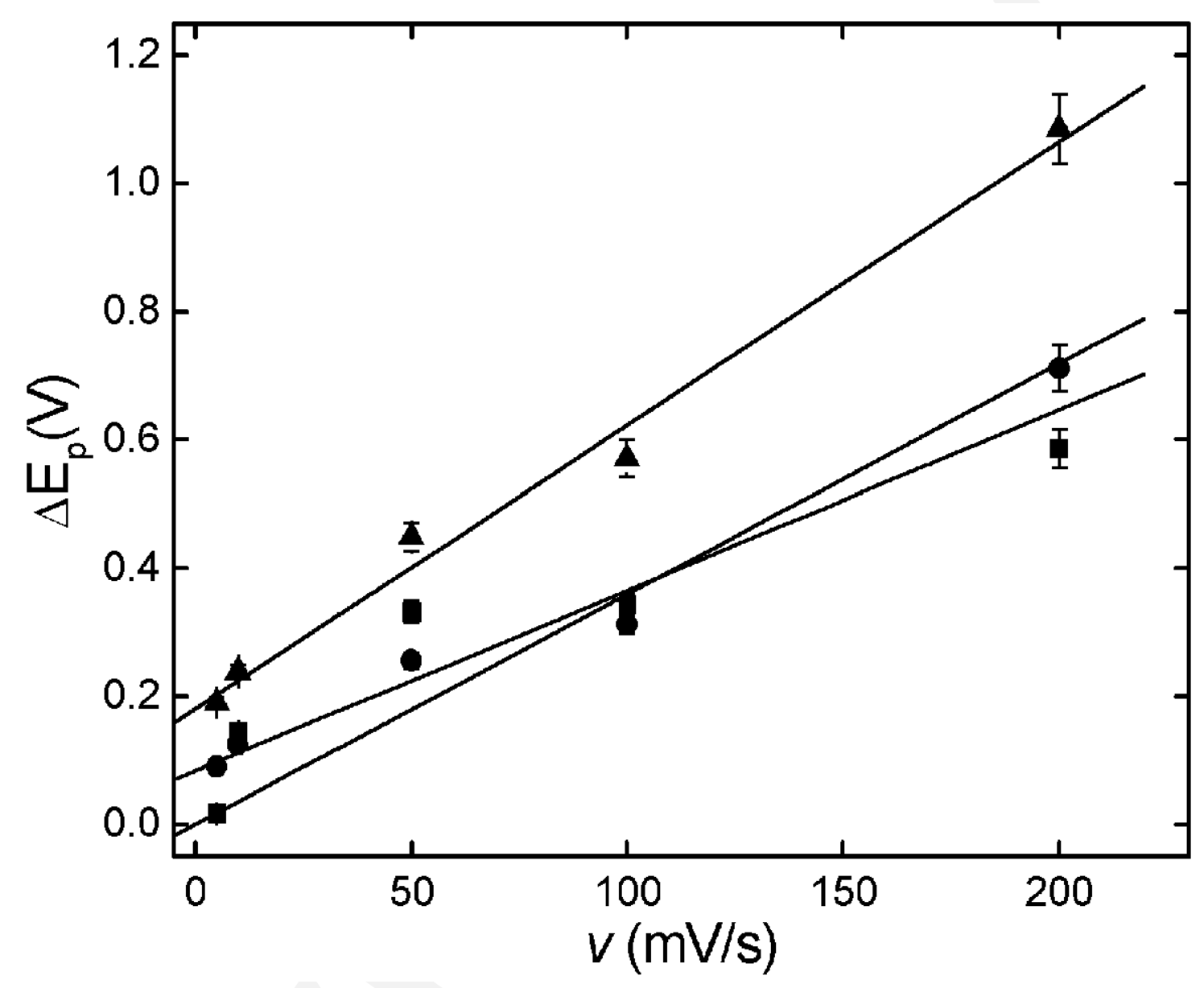

Figure 5 


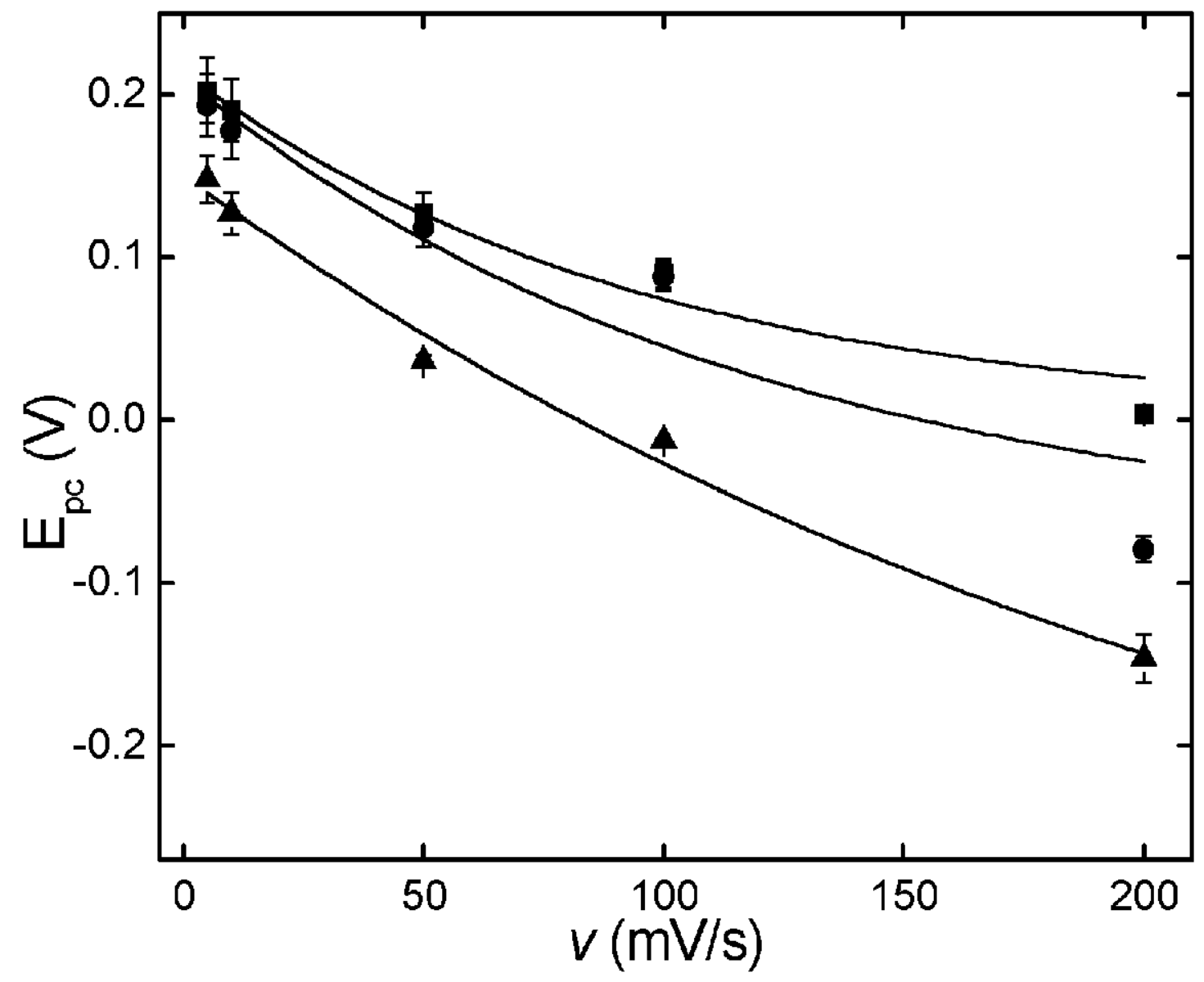

Figure 6. 


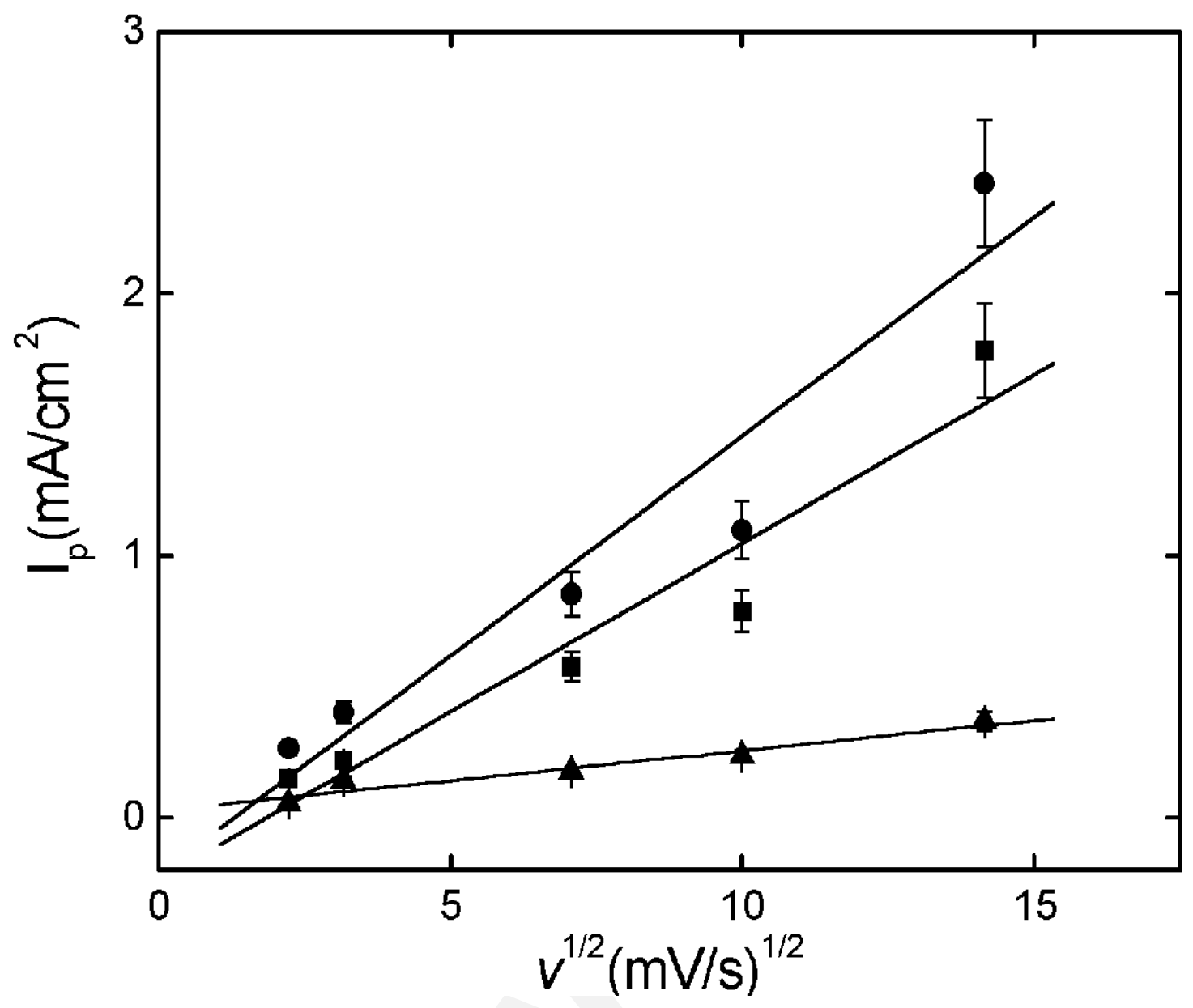

Figure 7 


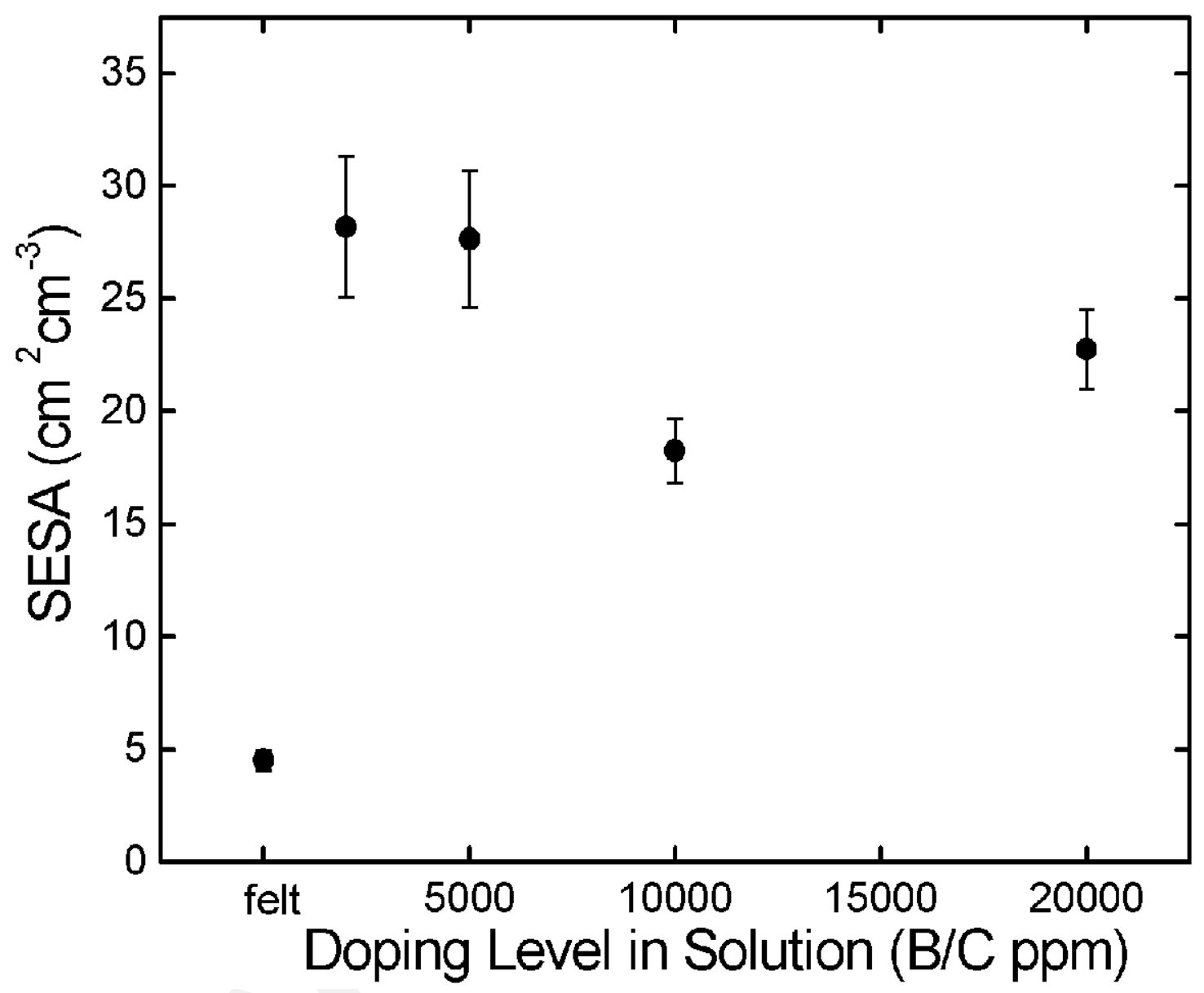

Figure 8 